\title{
Prioritizing quality improvement in pediatric cardiac surgery
}

\author{
Pirooz Eghtesady, MD, PhD, ${ }^{\mathrm{a}}$ Anoop K. Brar, PhD, ${ }^{\mathrm{a}}$ and Matthew Hall, $\mathrm{PhD}{ }^{\mathrm{b}}$
}

Background: Several efforts are under way to conduct quality-improvement initiatives in pediatric cardiology and cardiac surgery. Our goal was to develop an objective prioritization scheme for such initiatives based on encounter frequency and relative contribution of quality measures of morbidity (and associated variances), particularly in the setting of low mortality.

Methods: We identified patients in the Pediatric Health Information System in Risk Adjustment for Congenital Heart Surgery 1 category 1 to 6 for 32 pediatric cardiac surgical procedures conducted between 2003 and 2011 $(n=67,550)$. These were examined for their overall contribution to mortality, intensive care unit and hospital lengths of stay (coefficient of variation and excess days), adverse events, and readmission rates. A ranking scheme was created on the basis of the outcome measures. Then we ordered the procedures across metrics to develop a prioritization scheme.

Results: Observed mortality rates were consistent with published rates. A few procedures accounted for significant variation in hospital and intensive care length of stay across the hospitals. Likewise, a few procedures accounted for most excess days of stay and readmission rates. Up to $60 \%$ of the hospital stay was accounted for by intensive care unit stay. Although there was a linear relationship between adverse event rates and Risk Adjustment for Congenital Heart Surgery 1 categories, a few procedures once again accounted for disproportionate event rates within and across their respective Risk Adjustment for Congenital Heart Surgery 1 categories.

Conclusions: A small number of procedures account for a substantial burden of morbidity, even among low mortality risk groups. Consideration should be given to using such objective prioritization schemes to develop targeted quality-improvement measures. (J Thorac Cardiovasc Surg 2013;145:631-40)

Earn CME credits at

http://cme.ctsnetjournals.org

There is growing interest in measuring and improving the quality of care in pediatric cardiac surgery. Historically, the outcome measure of greatest interest has been mortality, with risk stratification schemes and effects of perioperative care measures being defined by their impact on mortality. However, it is increasingly being recognized that mortality by itself is an inadequate marker of quality, particularly with improving mortality data. ${ }^{1-4}$ Further, the riskstratification systems that were originally developed on the basis of mortality data may not allow understanding of both processes and outcomes that are specific to

From the Division of Pediatric Cardiothoracic Surgery, ${ }^{a}$ Washington University School of Medicine, St Louis, Mo; and Children's Hospital Association, ${ }^{\mathrm{b}}$ Overland Park, Kan.

Disclosures: Authors have nothing to disclose with regard to commercial support.

Read at the 38th Annual Meeting of The Western Thoracic Surgical Association,

Maui, Hawaii, June 27-30, 2012.

Received for publication June 22, 2012; revisions received Oct 26, 2012; accepted for publication Dec 5, 2012.

Address for reprints: Pirooz Eghtesady, MD, PhD, Division of Pediatric Cardiothoracic Surgery, Washington University School of Medicine, Campus Box 8234, St Louis, MO 63110 (E-mail: eghtesadyp@wudosis.wustl.edu).

$0022-5223 / \$ 36.00$

Copyright (c) 2013 by The American Association for Thoracic Surgery http://dx.doi.org/10.1016/j.jtcvs.2012.12.018 individual operations that significantly contribute to quality of care, for example, length of stay (LOS) or complications.

Some professional bodies, such as the American College of Surgeons National Quality Improvement Program, are moving toward procedure-specific measures of performance, ${ }^{5-9}$ basing the decision on various initiatives based on relative contribution of those specific procedures to observed outcome measures. Others, such as the American College of Cardiology Adult Congenital and Pediatric Cardiology working group, are using consensus or expert opinion to guide the selection of a quality improvement (QI) initiative.

From the perspective of QI, it makes sense to consider the extent to which different operations contribute to overall morbidity and mortality. Such an approach should account for how frequently the operation is performed and its underlying complication rate. Alternatively, procedures could be prioritized according to the excess cost or LOS attributable to procedure-associated complications. Further, evidence of significant variation in outcome measures and related practice patterns could highlight an opportunity for QI efforts that optimize best practices for the affected population and, thereby, reduce such variances. In this context, our goal was to develop an objective approach for creating a prioritization scheme for targeting QI efforts at commonly performed pediatric cardiac surgical procedures. Specifically, we describe the relative contribution of different pediatric cardiac surgical procedures to length of intensive care unit 


\begin{tabular}{|c|c|}
\hline \multicolumn{2}{|c|}{ Abbreviations and Acronyms } \\
\hline ASD & $=$ atrial septal defect \\
\hline ECMO & $=$ extracorporeal membrane oxygenation \\
\hline HLHS & $=$ hypoplastic left heart syndrome \\
\hline ICU & $=$ intensive care unit \\
\hline LOS & $=$ length of stay \\
\hline PA & $=$ pulmonary artery \\
\hline PHIS & $=$ Pediatric Health Information System \\
\hline QI & $=$ quality improvement \\
\hline RACHS-1 & $\begin{aligned}= & \text { Risk Adjustment for Congenital Heart } \\
& \text { Surgery } 1\end{aligned}$ \\
\hline TAPVC & $\begin{array}{l}=\text { total anomalous pulmonary venous } \\
\text { connection }\end{array}$ \\
\hline VSD & $=$ ventricular septal defect \\
\hline
\end{tabular}

(ICU) and hospital LOS, the associated variances, adverse events, and readmission rates while accounting for their potential contribution to mortality.

\section{MATERIALS AND METHODS Study Cohort}

We used data from the Pediatric Health Information System (PHIS) database (Children's Hospital Association, Overland Park, Kan) from 2003 to 2011. Hospital-level exclusions included elimination of data from any hospitals with less than 3 years of data $(n=3$ hospitals $)$ and excluding from the analysis to those centers that had a greater than $30 \%$ change in their annual cardiac surgery volume during the period of study ( $n=5$ hospitals). The purpose of this latter exclusion was to limit data to those centers that were not in a state of flux (ie, focus on stable systems). Therefore, deidentified pediatric cardiac surgical cases reported by 35 participating hospitals were chosen for analysis. The identified cohort was then categorized into 54 procedures on the basis of the Risk Adjustment for Congenital Heart Surgery 1 (RACHS-1) classification system. ${ }^{10,11}$ Further, we wanted to focus on "common" procedures. Consequently, procedures with a frequency of less than 300 cases (ie, $\leq 1$ case annually at any particular institution) were not included in the analysis. Because RACHS- 1 does not have any exclusion criteria based on age for many procedures, to avoid computing outcomes from heterogeneous age populations, we implemented a patient-level exclusion based on age. Outliers that were outside 2 standard deviations from the $50 \%$ trimmed mean $(n=38,815$ subjects excluded) within each procedure. Further, if there were multiple procedures during a single admission, we chose the procedure with the highest RACHS-1 score as the primary procedure. On the basis of the preceding, from the original 54 procedure codes, 32 procedures were identified for further data retrieval and analysis according to their overall contribution to the total case volume within their respective risk category (Figure 1). In this report, ventricular septal defect (VSD) repair associated with an atrial septal defect (ASD) repair and the isolated VSD groups were combined into 1 category/procedure. We elected not to study the neonatal patent ductus arteriosus ligation procedure group (category 1 procedure) because many patients undergoing this procedure potentially have other comorbidities that could account for their LOS or mortality beyond the surgery. Further, on the basis of the inclusion/exclusion criteria we used, category 5 procedures (mainly related to truncus arteriosus repair associated with interruption of aortic arch) were excluded because there were too few cases. Last, we limited the neonatal coarctation repair cohort to those done without the use of cardiopulmonary bypass (ie, eliminated $23 \%$ of neonatal coarctation repair cases) to maintain a more homogenous population. We were particularly interested in focusing on commonly performed procedures that are expected to have relatively low mortality rates (eg, RACHS-1 category 1-4) but wanted to compare them with higher mortality procedures, such as the Norwood procedure. There are already many ongoing QI research projects, such as the Pediatric Heart Network-funded Single Ventricle Reconstruction study or the Joint Commission for Congenital Heart Disease study, which are focused on improving outcomes after the Norwood procedure. Therefore, we wanted to identify other areas with a potentially high impact on the population with congenital heart disease (because of a high frequency of encounter across many institutions).

\section{Outcomes}

Outcome variables assessed in this study included mortality during the hospital admission, LOS in the hospital or ICU (and associated coefficient of variation), adverse event rates based on modifications of a prior coding algorithm, ${ }^{12}$ and readmissions within 14 days after hospital discharge.

\section{Analysis}

Expected mortality was calculated as previously described. ${ }^{13}$ We examined mortality outcomes for each procedure comparing with previously reported data for RACHS-1 criteria using Flora's $z$ test. ${ }^{14}$ We evaluated procedures according to overall hospital LOS, ICU LOS, and readmission rates within 14 days after discharge. We calculated medians with interquartile ranges (25th-75th percentile) for each variable, where applicable. Although we reasoned that ICU LOS would directly be proportional to associated postoperative morbidity that would complicate postoperative care, as shown by others, ${ }^{15}$ we also looked at adverse event rates using modification of a previously validated algorithm. We included the use of extracorporeal membrane oxygenation (ECMO) during that hospital admission as an additional event category because it is an important and critical component for pediatric patients with cardiac disease. We also assessed the correlation between hospital LOS and ICU LOS to determine the degree of ICU stay contribution to overall LOS using Spearman's correlation. For binary outcomes, we compared rates within and across RACHS- 1 categories using generalized estimating equations to account for hospital clustering. For continuous outcomes, we made comparisons using mixed models to account for hospital clustering by including "hospital" as a random effect. We then ordered the procedures according to their contribution to the total case volumes, relative contribution to mortality, relative contribution to readmission within 14 days, and excess LOS. Excess LOS was defined as observed minus expected LOS if the observed was greater than the expected, and zero otherwise. Expected LOS for each procedure was calculated as the average LOS in the Healthcare Cost and Utilization Project Kids' Inpatient Database 2009 database. As a "tie-breaker" among procedures without any associated excess LOS, we used the coefficient of variation as a further discriminatory factor to tease out procedures with high versus low variation in LOS. Finally, we summed the ranks across the variables for each procedure as an example prioritization scheme. All analyses were performed with SAS version 9.2 (SAS Institute, Inc, Cary, NC).

\section{RESULTS}

\section{Demographics and Volume}

Pediatric cardiac procedure cases RACHS-1 categories 1 to 6 from 2003 to 2011 were identified in the PHIS database. After application of hospital- and patient-level exclusion criteria, 67,550 cases from 35 contributing hospitals were selected for further analysis. From this cohort, we focused on 32 procedure groups because they were the primary procedures within their respective RACHS-1 categories and allowed for sufficient numbers of cases for procedure-level analyses. The demographics of the cohort, including gender, race, age, disposition, payor, RACHS-1 category, and LOS in 


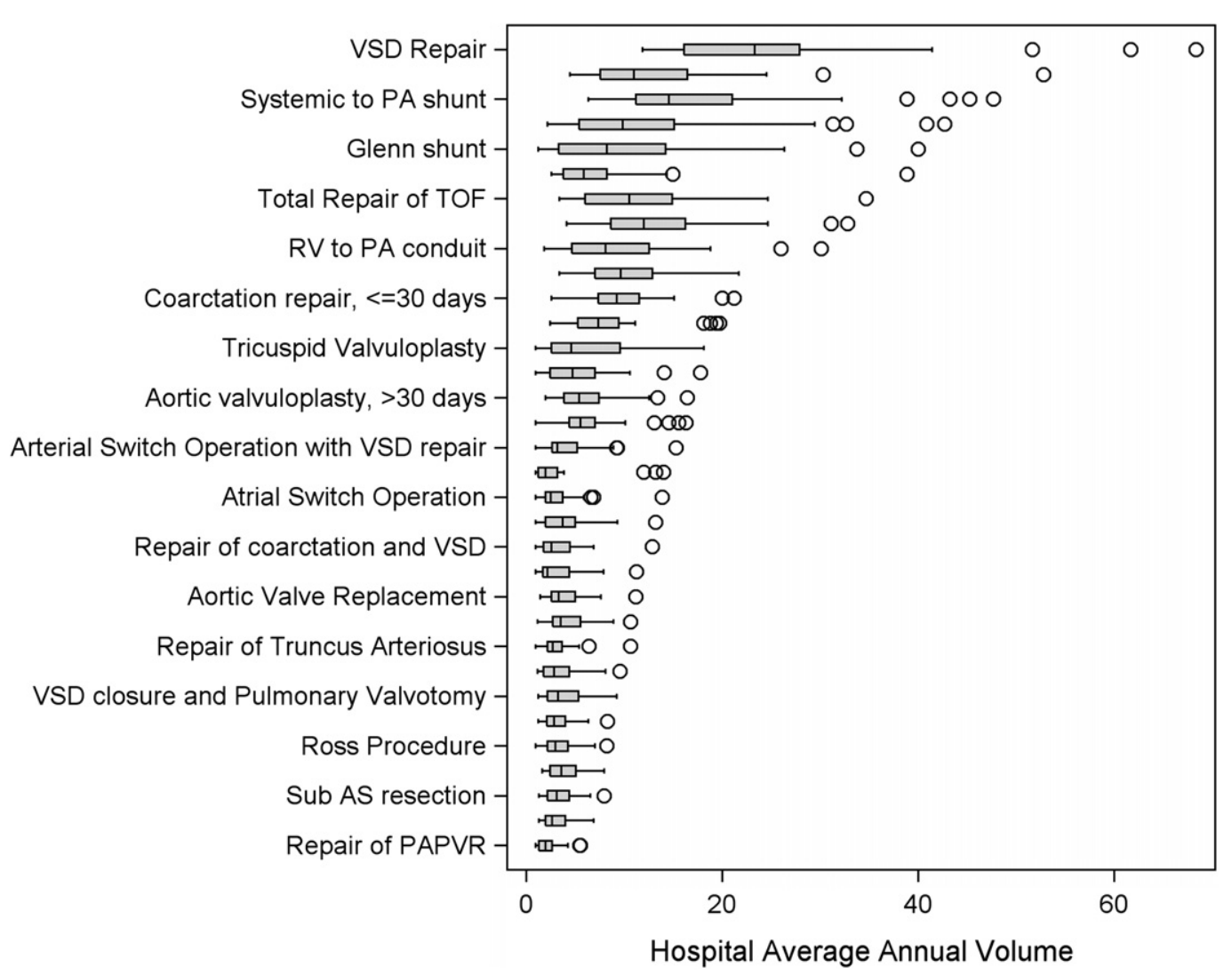

FIGURE 1. Average annual volume for each procedure. VSD, Ventricular septal defect; $A S D$, atrial septal defect; $P A$, pulmonary artery; TOF, tetralogy of Fallot; $A V C$, atrioventricular canal; $R V$, right ventricle; $P A$, pulmonary artery; $H L H S$, hypoplastic left heart syndrome; TAPVR, total anomalous pulmonary venous return; IAA, interruption of aortic arch; RVOT, right ventricular outflow tract; $A S$, aortic stenosis; PAPVR, partial anomalous venous return.

hospital, are displayed in Table 1. For all hospitals, the majority of cases were in RACHS-1 categories 2 and 3. The distribution of cases based on RACHS-1 categories was $11.2 \%$ for category $1(\mathrm{n}=7552), 38.4 \%$ for category $2(\mathrm{n}=25,925)$, $41.3 \%$ for category $3(n=27,896), 6.1 \%$ for category 4 $(\mathrm{n}=4115)$, and $3.1 \%(\mathrm{n}=2062)$ for category 6 . Figure 1 shows the distribution of the average annual volume for each procedure across the hospitals. The largest portion of cases in our dataset were VSD repairs, followed by secundum ASD and then systemic-to-pulmonary artery (PA) shunts.

\section{Length of Stay}

The overall hospital LOS and ICU LOS for the procedure groups are shown in Table 2. The ICU LOS data followed the same pattern as seen for hospital LOS. The ICU LOS variability accounted for approximately $30 \%$ to $50 \%$ of overall hospital LOS without any direct correlation to the RACHS-1 complexity. RACHS-1 classification was originally designed for comparing mortality measures (and not, eg, LOS). Nevertheless, increasing RACHS-1 risk category was associated overall with a longer ICU and hospital LOS $(P<.001)$.

All cases were performed with bypass with the exception of coarctation repair at 30 days or less $(0 \%)$ and in $11.4 \%$ of coarctation repairs at 30 days or more. Other procedures in which bypass was conducted in a proportion of the subjects were systemic-to-PA shunts $(54.6 \%)$, Glenn shunts $(88.8 \%)$, and the Fontan procedure $(88.8 \%)$.

However, there were significant differences in median hospital and ICU LOS within RACHS-1 risk categories. The overall difference between ICU and hospital LOS averaged only 4.5 days for RACHS- 1 category 1 to 3 cases, increasing suddenly to 14 days with RACHS- 1 categories 4 to 6. Systemic-to-PA shunt procedures (difference of 14 days) and coarctation/VSD repair groups (difference of 10 days) accounted for approximately all of the difference of hospital versus ICU days in the lower RACHS-1 groups. In contrast, the RACHS- 1 categories 4 to 6 were tightly grouped around 12 to 17 days difference. The total excess days for each procedure (observed LOS - expected LOS) are displayed in Table 2. A few procedures accounted for approximately all excess days among all encounters: Systemicto-PA shunt, mitral valvuloplasty, and repairs of coarctation and VSD had the greatest number of excess days, each contributing more than 2000 excess days of stay. Last, even among procedures with no associated excess days and overall short LOS (hospital or ICU), a few were associated with significantly greater variation among various hospitals. For example, resection of subaortic membrane was associated 
TABLE 1. Demographics of cohort

\begin{tabular}{|c|c|}
\hline & $\mathbf{N}(\%)$ \\
\hline \multicolumn{2}{|l|}{ Gender } \\
\hline a. Male & $37,641(55.7)$ \\
\hline b. Female & $29,900(44.3)$ \\
\hline \multicolumn{2}{|l|}{ Race } \\
\hline a. Non-Hispanic white & $35,805(57.2)$ \\
\hline b. Non-Hispanic black & $6970(11.1)$ \\
\hline c. Hispanic & $12,717(20.3)$ \\
\hline d. Asian & $1892(3)$ \\
\hline e. Other & $5184(8.3)$ \\
\hline \multicolumn{2}{|l|}{ Age } \\
\hline a. $<2 \mathrm{y}$ & $48,855(72.3)$ \\
\hline b. $2-4$ y & $10,859(16.1)$ \\
\hline c. $5-9$ y & $4079(6)$ \\
\hline d. $10-14 \mathrm{y}$ & $2362(3.5)$ \\
\hline e. $15-18$ y & $1324(2)$ \\
\hline f. $>18 \mathrm{y}$ & $71(0.1)$ \\
\hline \multicolumn{2}{|l|}{ Disposition } \\
\hline \multicolumn{2}{|l|}{ a. Home 60,381 (89.4) } \\
\hline \multicolumn{2}{|l|}{ b. Died 1893 (2.8) } \\
\hline \multicolumn{2}{|l|}{ c. Other 5276 (7.8) } \\
\hline \multicolumn{2}{|l|}{ Payor } \\
\hline a. Government & $27,709(41)$ \\
\hline b. Private & $26,257(38.9)$ \\
\hline c. Other & $13,584(20.1)$ \\
\hline \multicolumn{2}{|l|}{ RACHS-1 category } \\
\hline 1 & $7552(11.2)$ \\
\hline 2 & $25,925(38.4)$ \\
\hline 3 & $27,896(41.3)$ \\
\hline 4 & $4115(6.1)$ \\
\hline 6 & $2062(3.1)$ \\
\hline \multicolumn{2}{|l|}{ Length of stay (d) } \\
\hline a. $1-5 \mathrm{~d}$ & $24,974(37)$ \\
\hline b. $6-10 \mathrm{~d}$ & $17,598(26.1)$ \\
\hline c. $11-15 \mathrm{~d}$ & $8218(12.2)$ \\
\hline d. $16+d$ & $16,760(24.8)$ \\
\hline
\end{tabular}

with less variation than repair of primum or secundum ASD. The differences in coefficients of variation were more noticeable for overall hospital LOS than ICU LOS.

\section{Adverse Events}

Overall, increasing RACHS-1 classification was associated with higher adverse event rate, although there were some notable exceptions, such as atrial switch procedure (3.6\% event rate) or sub-aortic stenosis resection $(4.1 \%)$ (Table 3). There were significant differences among different procedures for types of events. For example, rates of renal failure requiring dialysis were similar between various procedures, including higher risk categories. In contrast, risk of pneumonia or respiratory tract infection or need for ECMO support was concentrated among a few procedures. Overall event rate correlated with hospital and ICU LOS. The event rate was not substantially different between the RACHS-1 4 and 6 category procedures.

\section{Readmission Rates}

Data related to hospital readmission rates within 14 days from discharge are shown in Table 3. As expected, there were significant differences across the RACHS- 1 categories for readmission rates $(P<.001)$, with readmission rates progressively increasing with increasing risk classification. The highest readmission rate occurred for the Norwood stage 1 repair of hypoplastic left heart syndrome (HLHS) (category 4) and the Fontan procedure (category 3 ). However, readmission rates were also disparate within individual risk groups with significant differences between category 2 and 3 procedures (both $P<.001$ ); these were driven by the relatively high readmission rates for patients after the Glenn shunt (category 2) and Fontan (category 3) repair procedures, respectively.

\section{Mortality}

We compared the observed versus expected mortality groups on the basis of previously published RACHS-1 criteria. The selected 32 procedures were found to have mortality rates consistent with expected rates as previously described $^{10,11,14}$ (Table 3 ). The highest mortality rate was for the Norwood procedures (category 6), repair of total anomalous pulmonary venous return at 30 days or less (total anomalous pulmonary venous return; category 4 ), and the systemic-to-PA shunts (category 3 ).

\section{Prioritization Scheme}

Prioritization of the procedures according to their contribution to the total case volumes, relative contribution to mortality, relative contribution to readmission within 14 days, any adverse event, and excess LOS (with secondary discrimination based on coefficient of variation) is shown in Table 4. Although it might be desirable to order procedures according to only 1 of these metrics (eg, relative contribution to mortality), we have ordered the procedures on the basis of a balance of the metrics using ranks. Thus, the lower the sum of the rank for a procedure, the higher the priority for that procedure. With this approach, the top 3 ranked procedures (highest priority) are the systemic-toPA shunts, Fontan, and Norwood stage 1 repair for HLHS.

\section{DISCUSSION}

Our original goal was to focus on procedures that are commonly performed by many institutions and typically associated with low mortality; we included the Norwood procedure mainly for comparison/curiosity because there are a number of QI initiatives already directed at the latter. We were interested secondarily to see whether there were significant variations in care, anticipating more perturbations in any system that carries out these procedures with high frequency. We found that a small number of procedures (eg, systemic-to-PA shunts) account for 


\begin{tabular}{|c|c|c|c|c|c|c|c|c|c|}
\hline \multirow[b]{2}{*}{ RACHS } & \multirow[b]{2}{*}{ Procedure } & \multirow[b]{2}{*}{$\mathbf{N}$} & \multirow[b]{2}{*}{$\begin{array}{c}\text { Age in days } \\
\text { median (IQR) }\end{array}$} & \multirow[b]{2}{*}{$\%$ Bypass } & \multicolumn{3}{|c|}{ Overall } & \multicolumn{2}{|c|}{ ICU } \\
\hline & & & & & $\begin{array}{c}\text { Median } \\
\text { LOS (IQR) }\end{array}$ & $\begin{array}{c}\text { Total excess } \\
\text { days }\end{array}$ & CV & $\begin{array}{c}\text { Median } \\
\text { LOS (IQR) }\end{array}$ & CV \\
\hline 1 & ASD secundum repair & 4109 & $1350(895-1785)$ & 100.0 & $3(3-4)$ & 0 & 256.7 & $1(1-2)$ & 477.7 \\
\hline 1 & Coarctation repair, $>30 \mathrm{~d}$ & 3019 & $132(62-430)$ & 11.4 & $5(3-7)$ & 0 & 173.8 & $2(1-4)$ & 213.5 \\
\hline 1 & Repair of PAPVR & 424 & $1559(1068-2234)$ & 100.0 & $3(3-4)$ & 0 & 175.5 & $1(1-2)$ & 284.3 \\
\hline 2 & Aortic valvuloplasty, $>30 \mathrm{~d}$ & 1773 & $1858(1078-2789)$ & 100.0 & $4(3-5)$ & 0 & 180.9 & $1(1-2)$ & 314.8 \\
\hline 2 & ASD primum repair & 1037 & $389(165-829)$ & 100.0 & $4(3-7)$ & 0 & 247.4 & $2(1-3)$ & 239.8 \\
\hline 2 & Coarctation repair, $\leq 30 \mathrm{~d}$ & 2937 & $2(1-7)$ & 0.0 & $12(7-20)$ & 0 & 132.8 & $4(2-7)$ & 173.9 \\
\hline 2 & Glenn shunt & 3163 & $168(144-205)$ & 88.8 & $7(5-10)$ & 0 & 121.0 & $2(0-4)$ & 189.8 \\
\hline 2 & Pulmonary valve replacement & 1889 & $5123(4093-6022)$ & 100.0 & $4(3-5)$ & 0 & 96.4 & $2(1-3)$ & 153.5 \\
\hline 2 & Repair of TAPVR, $>30 \mathrm{~d}$ & 743 & $71(49-112)$ & 100.0 & $10(6-15)$ & 1718 & 205.1 & $4(2-8)$ & 176.4 \\
\hline 2 & RVOT procedure & 1069 & $309(148-769)$ & 100.0 & $5(4-8)$ & 0 & 182.8 & $2(1-4)$ & 271.0 \\
\hline 2 & Sub-AS resection & 728 & $1438(1014-2089)$ & 100.0 & $4(3-5)$ & 0 & 65.0 & $1(1-2)$ & 114.5 \\
\hline 2 & Total repair of TOF & 3557 & $139(107-176)$ & 100.0 & $6(5-9)$ & 0 & 103.3 & $3(2-5)$ & 136.7 \\
\hline 2 & $\begin{array}{l}\text { VSD closure and pulmonary } \\
\text { valvotomy }\end{array}$ & 989 & $189(117-272)$ & 100.0 & $5(4-8)$ & 0 & 106.4 & $2(1-4)$ & 141.2 \\
\hline 2 & VSD repair & 8040 & $138(89-207)$ & 100.0 & $5.5(4-9)$ & 0 & 138.6 & $2(1-4)$ & 182.6 \\
\hline 3 & Aortic valve replacement & 1047 & 5435 (4817-6186) & 100.0 & $6(5-8)$ & 1021 & 112.7 & $2(1-4)$ & 189.8 \\
\hline 3 & Arterial switch operation & 2505 & $0(0-1)$ & 100.0 & $15(12-21)$ & 0 & 85.2 & $7(3-11)$ & 135.7 \\
\hline 3 & Atrial switch operation & 741 & $1149(631-1702)$ & 100.0 & $4(3-6)$ & 0 & 116.8 & $1(1-3)$ & 176.7 \\
\hline 3 & Fontan procedure & 3969 & $1099(936-1262)$ & 93.4 & $9(7-13)$ & 1401 & 93.4 & $3(1-5)$ & 156.5 \\
\hline 3 & Mitral valve replacement & 786 & $3350(1661-4665)$ & 100.0 & $9(6-15)$ & 1889 & 96.8 & $3(1-6)$ & 151.3 \\
\hline 3 & Mitral valvuloplasty & 2170 & $738(238-1582)$ & 100.0 & $5(4-10)$ & 3047 & 152.8 & $2(1-4)$ & 223.9 \\
\hline 3 & $\begin{array}{l}\text { Repair of coarctation and } \\
\text { VSD }\end{array}$ & 836 & $3(1-8)$ & 100.0 & $18(13-31)$ & 2900 & 114.1 & $8(1-14)$ & 124.1 \\
\hline 3 & $\begin{array}{l}\text { Repair of TOF with RV-to-PA } \\
\text { conduit }\end{array}$ & 627 & $167(115-224)$ & 100.0 & $8(5-14)$ & 0 & 127.3 & $3(0-7)$ & 204.7 \\
\hline 3 & $\begin{array}{l}\text { Repair of transitional or } \\
\text { complete AVC }\end{array}$ & 4124 & $143(114-180)$ & 100.0 & $7(5-11)$ & 0 & 165.5 & $3(2-6)$ & 189.1 \\
\hline 3 & Ross procedure & 703 & 3683 (2176-4918) & 100.0 & $5(4-7)$ & 0 & 81.4 & $2(1-4)$ & 101.3 \\
\hline 3 & RV-to-PA conduit & 2832 & $643.5(215-2095)$ & 100.0 & $6(4-14)$ & 0 & 144.2 & $2(1-6)$ & 208.3 \\
\hline 3 & Systemic-to-PA shunt & 5755 & $1(0-2)$ & 54.6 & $20(13-34)$ & 7391 & 120.7 & $6(2-13)$ & 203.5 \\
\hline 3 & Tricuspid valvuloplasty & 1801 & $179(108-397)$ & 100.0 & $6(4-12)$ & 2023 & 175.5 & $3(1-6)$ & 214.2 \\
\hline 4 & $\begin{array}{l}\text { Arterial switch operation with } \\
\text { VSD repair }\end{array}$ & 1212 & $1(0-1)$ & 100.0 & $19(14-25)$ & 0 & 86.4 & $7(0-12)$ & 132.3 \\
\hline 4 & $\begin{array}{l}\text { Repair of hypoplastic aortic } \\
\operatorname{arch} / \text { IAA }\end{array}$ & 883 & $2(1-4)$ & 100.0 & $24(15-38)$ & 2101 & 102.7 & $8.5(2-15)$ & 140.7 \\
\hline 4 & Repair of TAPVR, $\leq 30 \mathrm{~d}$ & 1251 & $1(0-1)$ & 100.0 & $18(12-30)$ & 0 & 109.3 & $7(0.5-14)$ & 162.9 \\
\hline 4 & Repair of truncus arteriosus & 769 & $1(0-8)$ & 100.0 & $22(14-34)$ & 590 & 90.5 & $8(5-16)$ & 129.8 \\
\hline 6 & $\begin{array}{l}\text { Norwood: stage } 1 \text { repair of } \\
\text { HLHS }\end{array}$ & 1364 & $0(0-1)$ & 100.0 & $27(18-41)$ & 1334 & 70.2 & $12(0-21)$ & 117.3 \\
\hline 6 & $\begin{array}{l}\text { Norwood: stage } 1 \text { repair of } \\
\text { non-HLHS }\end{array}$ & 698 & $1(1-2)$ & 100.0 & $28(20-43)$ & 2126 & 77.6 & $11(0-19)$ & 135.2 \\
\hline
\end{tabular}

The 32 procedures chosen for the period of study are indicated with their respective RACHS-1 category designation, bypass rate, the cases or total number (N), and percent of the category (in parenthesis), followed by the age of the patient cohorts in days (median, with IQR). RACHS, Risk Adjustment for Congenital Heart Surgery; IQR, interquartile range; $L O S$, length of stay; $C V$, cardiovascular; $I C U$, intensive care unit; $A S D$, atrial septal defect; PAPVR, partial anomalous venous return; TAPVR, total anomalous pulmonary venous return; RVOT, right ventricular outflow tract; $A S$, aortic stenosis (produced by an obstruction in the left ventricle at the aortic valve); TOF, tetralogy of Fallot; VSD, ventricular septal defect; $R V$, right ventricle; $P A$, pulmonary artery; $A V C$, atrioventricular canal; $I A A$, interruption of aortic arch; $H L H S$, hypoplastic left heart syndrome.

a disproportionate burden of less than optimal outcomes among these commonly performed procedures. We also observed, perhaps not surprisingly, that some of the relatively simple procedures had substantially higher variation in LOS (both hospital and ICU) compared with the more complex procedures. Likewise, a few procedures accounted for the highest burden of adverse event and readmission rates.
We also reanalyzed our data while censoring for mortality, and the results were not changed (data not shown). These findings suggest that QI measures directed at a few procedures may have significant impact for overall outcomes.

One of the important findings of our study was the quantification of significant variation in hospital and ICU LOS, particularly for relatively "low-risk" procedures and the 


\begin{tabular}{|c|c|c|c|c|c|c|c|c|c|c|}
\hline \multirow[b]{2}{*}{$\begin{array}{c}\text { RACHS } \\
\text { level }\end{array}$} & \multirow[b]{2}{*}{ Procedure } & \multicolumn{7}{|c|}{ Adverse events } & \multirow[b]{2}{*}{ Readmission } & \multirow[b]{2}{*}{ Mortality } \\
\hline & & $\begin{array}{l}\text { Acute renal } \\
\text { failure } \\
\text { requiring } \\
\text { dialysis } \\
\end{array}$ & $\begin{array}{c}\text { Pneumonia and } \\
\text { other lower } \\
\text { respiratory } \\
\text { infections } \\
\end{array}$ & $\begin{array}{c}\text { Wound } \\
\text { infection or } \\
\text { cellulitis } \\
\end{array}$ & $\begin{array}{c}\text { Sepsis } \\
\text { requiring } \\
\text { pressors } \\
\end{array}$ & $\begin{array}{c}\text { Cardiac } \\
\text { arrest or } \\
\text { dysrhythmia } \\
\text { requiring CPR }\end{array}$ & ECMO & $\begin{array}{c}\text { Any } \\
\text { event }\end{array}$ & & \\
\hline 1 & ASD secundum repair & 0.1 & 3.4 & 0.5 & 0.5 & 0.1 & 0.2 & 4.3 & 2.2 & 0.1 \\
\hline 1 & $\begin{array}{l}\text { Coarctation repair, } \\
>30 \mathrm{~d}\end{array}$ & 0.0 & 6.0 & 0.4 & 1.1 & 0.3 & 0.2 & 7.4 & 1.7 & 0.1 \\
\hline 1 & Repair of PAPVR & 0.0 & 2.8 & 0.0 & 0.0 & 0.2 & 0.0 & 3.1 & 0.9 & 0.0 \\
\hline 2 & $\begin{array}{l}\text { Aortic valvuloplasty, } \\
\quad>30 \mathrm{~d}\end{array}$ & 0.1 & 3.7 & 0.3 & 0.6 & 0.3 & 0.4 & 4.8 & 2.1 & 0.3 \\
\hline 2 & ASD primum repair & 0.1 & 6.1 & 1.1 & 1.9 & 0.3 & 0.3 & 8.0 & 2.6 & 0.7 \\
\hline 2 & $\begin{array}{l}\text { Coarctation repair, } \\
\leq 30 \mathrm{~d}\end{array}$ & 0.1 & 7.0 & 3.6 & 4.2 & 0.7 & 0.5 & 14.3 & 4.6 & 2.8 \\
\hline 2 & Glenn shunt & 0.0 & 12.3 & 3.6 & 1.8 & 0.7 & 0.6 & 16.5 & 6.1 & 1.8 \\
\hline 2 & $\begin{array}{l}\text { Pulmonary valve } \\
\text { replacement }\end{array}$ & 0.1 & 6.4 & 0.3 & 0.3 & 0.1 & 0.2 & 7.0 & 2.5 & 0.2 \\
\hline 2 & $\begin{array}{l}\text { Repair of TAPVR, } \\
>30 \mathrm{~d}\end{array}$ & 0.1 & 12.0 & 0.8 & 4.4 & 0.9 & 2.3 & 16.2 & 3.9 & 2.2 \\
\hline 2 & RVOT procedure & 0.4 & 9.9 & 1.0 & 2.5 & 0.8 & 0.7 & 13.3 & 2.7 & 2.2 \\
\hline 2 & Sub-AS resection & 0.1 & 2.3 & 0.1 & 1.4 & 0.0 & 0.3 & 4.1 & 0.8 & 0.1 \\
\hline 2 & Total repair of TOF & 0.0 & 9.5 & 1.1 & 2.1 & 0.5 & 0.6 & 12.3 & 2.9 & 0.3 \\
\hline 2 & $\begin{array}{l}\text { VSD closure and } \\
\text { pulmonary } \\
\text { valvotomy }\end{array}$ & 0.1 & 7.2 & 1.1 & 2.3 & 0.7 & 1.8 & 11.8 & 2.6 & 1.8 \\
\hline 2 & VSD repair & 0.0 & 9.0 & 0.9 & 1.7 & 0.3 & 0.5 & 11.6 & 2.9 & 0.4 \\
\hline 3 & $\begin{array}{l}\text { Aortic valve } \\
\text { replacement }\end{array}$ & 0.5 & 6.8 & 1.4 & 2.5 & 0.6 & 0.8 & 11.2 & 5.7 & 1.0 \\
\hline 3 & $\begin{array}{l}\text { Arterial switch } \\
\text { operation }\end{array}$ & 0.1 & 6.3 & 6.2 & 4.0 & 0.4 & 4.6 & 18.8 & 2.7 & 2.6 \\
\hline 3 & $\begin{array}{c}\text { Atrial switch } \\
\text { operation }\end{array}$ & 0.0 & 3.2 & 0.3 & 0.1 & 0.0 & 0.3 & 3.6 & 2.6 & 0.1 \\
\hline 3 & Fontan procedure & 0.5 & 14.4 & 2.8 & 2.5 & 0.4 & 1.0 & 18.3 & 9.0 & 1.8 \\
\hline 3 & $\begin{array}{l}\text { Mitral valve } \\
\text { replacement }\end{array}$ & 0.8 & 10.2 & 2.4 & 5.5 & 1.1 & 1.7 & 17.2 & 5.2 & 2.8 \\
\hline 3 & Mitral valvuloplasty & 0.1 & 10.1 & 1.3 & 2.0 & 1.3 & 1.2 & 13.8 & 3.8 & 1.5 \\
\hline 3 & $\begin{array}{l}\text { Repair of coarctation } \\
\text { and VSD }\end{array}$ & 0.1 & 10.3 & 5.5 & 6.3 & 1.3 & 2.4 & 20.8 & 4.4 & 3.0 \\
\hline 3 & $\begin{array}{l}\text { Repair of TOF with } \\
\text { RV-to-PA conduit }\end{array}$ & 1.6 & 14.0 & 1.4 & 5.4 & 1.4 & 3.5 & 20.9 & 4.1 & 0.8 \\
\hline 3 & $\begin{array}{l}\text { Repair of transitional } \\
\text { or complete AVC }\end{array}$ & 0.1 & 11.0 & 1.7 & 2.4 & 0.7 & 0.9 & 14.5 & 4.9 & 0.9 \\
\hline 3 & Ross procedure & 0.1 & 7.4 & 0.1 & 1.3 & 0.6 & 0.9 & 10.1 & 3.1 & 0.6 \\
\hline 3 & RV-to-PA conduit & 0.2 & 10.6 & 2.9 & 3.0 & 1.2 & 2.4 & 16.7 & 4.5 & 2.9 \\
\hline 3 & Systemic-to-PA shunt & 0.2 & 6.5 & 8.3 & 5.5 & 2.4 & 6.3 & 24.3 & 5.5 & 9.3 \\
\hline 3 & $\begin{array}{l}\text { Tricuspid } \\
\text { valvuloplasty }\end{array}$ & 0.0 & 9.6 & 1.3 & 2.6 & 0.6 & 0.8 & 14.4 & 4.9 & 1.6 \\
\hline 4 & $\begin{array}{l}\text { Arterial switch } \\
\text { operation with VSD } \\
\text { repair }\end{array}$ & 0.8 & 11.2 & 8.2 & 5.0 & 1.1 & 6.0 & 30.6 & 2.9 & 4.9 \\
\hline 4 & Repair of hypo/IAA & 0.9 & 9.7 & 7.5 & 8.6 & 0.7 & 4.5 & 31.0 & 5.8 & 7.0 \\
\hline 4 & $\begin{array}{l}\text { Repair of TAPVR, } \\
\leq 30 \mathrm{~d}\end{array}$ & 1.4 & 9.2 & 6.6 & 7.0 & 2.2 & 12.3 & 29.0 & 4.6 & 15.3 \\
\hline 4 & $\begin{array}{l}\text { Repair of truncus } \\
\text { arteriosus }\end{array}$ & 0.5 & 10.4 & 9.4 & 9.2 & 2.1 & 6.4 & 32.6 & 4.6 & 8.1 \\
\hline
\end{tabular}




\begin{tabular}{|c|c|c|c|c|c|c|c|c|c|c|}
\hline \multirow[b]{2}{*}{$\begin{array}{c}\text { RACHS } \\
\text { level }\end{array}$} & \multirow[b]{2}{*}{ Procedure } & \multicolumn{7}{|c|}{ Adverse events } & \multirow[b]{2}{*}{ Readmission } & \multirow[b]{2}{*}{ Mortality } \\
\hline & & $\begin{array}{l}\text { Acute renal } \\
\text { failure } \\
\text { requiring } \\
\text { dialysis }\end{array}$ & $\begin{array}{c}\text { Pneumonia and } \\
\text { other lower } \\
\text { respiratory } \\
\text { infections }\end{array}$ & $\begin{array}{l}\text { Wound } \\
\text { infection or } \\
\text { cellulitis }\end{array}$ & $\begin{array}{l}\text { Sepsis } \\
\text { requiring } \\
\text { pressors }\end{array}$ & $\begin{array}{c}\text { Cardiac } \\
\text { arrest or } \\
\text { dysrhythmia } \\
\text { requiring CPR }\end{array}$ & ECMO & $\begin{array}{c}\text { Any } \\
\text { event }\end{array}$ & & \\
\hline 6 & $\begin{array}{l}\text { Norwood: stage } 1 \\
\text { repair of HLHS }\end{array}$ & 0.7 & 10.0 & 9.4 & 8.7 & 3.7 & 10.3 & 35.0 & 9.5 & 16.2 \\
\hline 6 & $\begin{array}{l}\text { Norwood: stage } 1 \\
\quad \text { repair of non-HLHS }\end{array}$ & 1.6 & 12.2 & 9.3 & 10.5 & 3.6 & 14.9 & 36.5 & 6.0 & 15.6 \\
\hline
\end{tabular}

Adverse events for the different procedures and readmission and mortality rates are shown. RACHS, Risk Adjustment for Congenital Heart Surgery; $C P R$, cardiopulmonary resuscitation; $E C M O$, extracorporeal membrane oxygenation; $A S D$, atrial septal defect; $P A P V R$, partial anomalous venous return; TAPVR, total anomalous pulmonary venous return; $R V O T$, right ventricular outflow tract; $A S$, aortic stenosis (produced by an obstruction in the left ventricle at the aortic valve); TOF, tetralogy of Fallot; VSD, ventricular septal defect; $R V$, right ventricle; $P A$, pulmonary artery; $A V C$, atrioventricular canal; $I A A$, interruption of aortic arch; $H L H S$, hypoplastic left heart syndrome

overall contribution to excess LOS. These are potentially good targets for QI efforts and perhaps a subject of collaborative work groups as has been done in the adult cardiac care setting (eg, New England Collaborative). Potential standardization of care and learning from the best may lead to decreased variance and potentially improved outcomes. Also, further analysis of these data will allow identification of mitigating factors that may be modifiable and result in lower variance. Our data also show that the ICU LOS on average accounted for approximately $60 \%$ of all variation in hospital LOS. ICU LOS likely serves as a surrogate of complications that result in longer ICU stay, as suggested by others. ${ }^{15}$ Of note, in our study the patient age was adjusted to take out outliers that would have a significant impact on these findings (eg, ASD repair in a neonate is likely driven by different circumstances vs that in a 3year-old). Therefore, the observed variances likely reflect system-dependent factors that can be modified.

We found that a few procedures accounted for the substantial burden of adverse event and readmissions, with once again the Norwood stage 1 repair of HLHS, Fontan procedures, and Glenn shunt accounting for the greatest contributions. QI measures are already ongoing to improve outcomes after the Norwood procedure; additional QI measures that focus on the Fontan and Glenn procedures could further improve the continuum of care for these patients with single-ventricle physiology. Are the increased readmissions mainly related to recurrent pleural effusions that occur secondary to premature reduction or discontinuation of diuretic regimen? Moreover, patients undergoing systemic-to-PA shunting contributed significantly to readmissions, but with their already high baseline LOS, these patients have one of the longest hospital stays (ie, by combining the initial and readmit hospitalizations). Are these higher readmission rates because the patients are discharged too soon or is it reflective of inadequate anticoagulation regimens leading to recurrent shunt thrombosis or other technical parameters in play that need to be addressed? Whether systemic-toPA shunt procedures are amenable to intervention or are an inherent risk factor for the patient population who undergo this procedure ${ }^{16}$ deserves further investigation.
Our mortality data were consistent overall with prior reports using the RACHS-1 classification. ${ }^{10,11,14}$ Further, our results are consistent with limited procedure-specific mortality data recently published. ${ }^{13,17,18}$ These data suggest that overall outcomes for certain procedures have improved since inception of the RACHS-1 classification system (eg, for patients undergoing the Fontan or repair of complete atrioventricular canal), but continues to be problematic for a subset of babies, for example, those undergoing systemic-to-PA shunting. Whether the latter reflects a nonmodifiable risk factor based on the unique high-risk patient population versus modifiable elements for that procedure remains to be seen. Although we analyzed total anomalous pulmonary venous return procedures as 2 separate groups based on their median age, at 30 days or less and 30 days or more (neonates) this may not be ideal. The neonates may be cases who were missed at 30 days or less and may be presenting later for urgent interventions. The group aged more than 30 days also may be patients with nonobstructed total anomalous pulmonary venous connection (TAPVC) performed electively, especially those with cardiac TAPVC and a few with supracardiac TAPVC. The Society of Thoracic Surgeons-European Association for Cardio-Thoracic Surgery Congenital Heart mortality categories, ${ }^{13}$ which represent an alternative methodology for calculation and reporting of mortality outcomes, could overcome the limitations of coding encountered by using the RACHS- 1 categories .

\section{Study Limitations}

It is important to acknowledge the potential limitations of this study. The first limitation is that our database is substantially overrepresented by large teaching hospitals. Of the 35 hospitals that participated in our study, only 1 was not a teaching hospital. Academic hospitals may differ from community hospitals with regard to their procedure mix and other outcome measures. Both factors could affect the generalization of our findings. Also, the usual limitation of an administrative database (eg, lacking detailed clinical data, variations in coding accuracy, and limitations of International Classification of Diseases, 9th and 10th Revision codes for diagnosis and 
TABLE 4. Prioritization scheme based on ranks

\begin{tabular}{|c|c|c|c|c|c|c|c|c|c|c|c|c|}
\hline \multirow[b]{2}{*}{$\begin{array}{c}\text { RACHS } \\
\text { level }\end{array}$} & \multirow[b]{2}{*}{ Procedure } & \multicolumn{2}{|c|}{ Any event } & \multicolumn{2}{|c|}{ Readmission } & \multicolumn{2}{|c|}{ Mortality } & \multicolumn{3}{|c|}{ LOS } & \multirow[b]{2}{*}{ Sum rank } & \multirow[b]{2}{*}{ Priority } \\
\hline & & $\%$ Total & Rank & $\%$ Total & Rank & $\%$ Total & Rank & $\begin{array}{c}\% \text { Excess } \\
\text { total }\end{array}$ & Rank & $\begin{array}{l}\text { Mod } \\
\text { rank* }\end{array}$ & & \\
\hline 1 & ASD secundum repair & 1.7 & 19 & 3.2 & 10 & 0.3 & 25 & 0.0 & 13 & 13 & 67 & 17 \\
\hline 1 & Coarctation repair, $>30 \mathrm{~d}$ & 2.2 & 18 & 1.9 & 16 & 0.2 & 28 & 0.0 & 13 & 18 & 80 & 23 \\
\hline 1 & Repair of PAPVR & 0.1 & 33 & 0.1 & 33 & 0.0 & 33 & 0.0 & 13 & 17 & 116 & 30 \\
\hline 2 & Aortic valvuloplasty, $>30 \mathrm{~d}$ & 0.8 & 28 & 1.3 & 21 & 0.3 & 26 & 0.0 & 13 & 16 & 91 & 25 \\
\hline 2 & ASD primum repair & 0.8 & 29 & 1.0 & 27 & 0.4 & 24 & 0.0 & 13 & 14 & 94 & 26 \\
\hline 2 & Coarctation repair, $\leq 30 \mathrm{~d}$ & 4.1 & 10 & 4.8 & 6 & 4.4 & 5 & 0.0 & 13 & 23 & 44 & 9 \\
\hline 2 & Glenn shunt & 5.1 & 5 & 6.9 & 5 & 3.0 & 12 & 0.0 & 13 & 24 & 46 & 10 \\
\hline 2 & Pulmonary valve replacement & 1.3 & 23 & 1.7 & 18 & 0.2 & 30 & 0.0 & 13 & 29 & 100 & 27 \\
\hline 2 & Repair of TAPVR, $>30 \mathrm{~d}$ & 1.2 & 25 & 1.0 & 26 & 0.8 & 21 & 6.2 & 8 & 8 & 80 & 23 \\
\hline 2 & RVOT procedure & 1.4 & 21 & 1.0 & 25 & 1.3 & 18 & 0.0 & 13 & 15 & 79 & 22 \\
\hline 2 & Sub-AS resection & 0.3 & 31 & 0.2 & 32 & 0.1 & 32 & 0.0 & 13 & 33 & 128 & 33 \\
\hline 2 & Total repair of TOF & 4.2 & 9 & 3.7 & 9 & 0.5 & 23 & 0.0 & 13 & 28 & 69 & 19 \\
\hline 2 & $\begin{array}{l}\text { VSD closure and pulmonary } \\
\text { valvotomy }\end{array}$ & 1.1 & 27 & 0.9 & 28 & 1.0 & 20 & 0.0 & 13 & 27 & 102 & 28 \\
\hline 2 & VSD repair & 9.1 & 2 & 8.2 & 3 & 1.8 & 14 & 0.0 & 13 & 21 & 40 & 4 \\
\hline 3 & Aortic valve replacement & 1.1 & 26 & 2.1 & 14 & 0.5 & 22 & 3.7 & 11 & 11 & 73 & 20 \\
\hline 3 & Arterial switch operation & 4.6 & 8 & 2.4 & 13 & 3.5 & 8 & 0.0 & 13 & 31 & 60 & 14 \\
\hline 3 & Atrial switch operation & 0.3 & 32 & 0.7 & 31 & 0.1 & 31 & 0.0 & 13 & 25 & 119 & 31 \\
\hline 3 & Fontan procedure & 7.1 & 3 & 12.8 & 1 & 3.7 & 7 & 5.1 & 9 & 9 & 20 & 2 \\
\hline 3 & Mitral valve replacement & 1.3 & 22 & 1.5 & 20 & 1.2 & 19 & 6.9 & 7 & 7 & 68 & 18 \\
\hline 3 & Mitral valvuloplasty & 2.9 & 13 & 3.0 & 12 & 1.7 & 15 & 11.1 & 2 & 2 & 42 & 7 \\
\hline 3 & $\begin{array}{l}\text { Repair of coarctation and } \\
\text { VSD }\end{array}$ & 1.7 & 20 & 1.3 & 22 & 1.3 & 17 & 10.5 & 3 & 3 & 62 & 16 \\
\hline 3 & $\begin{array}{l}\text { Repair of TOF with RV-to-PA } \\
\text { conduit }\end{array}$ & 1.3 & 24 & 0.9 & 29 & 0.3 & 27 & 0.0 & 13 & 22 & 102 & 28 \\
\hline 3 & $\begin{array}{l}\text { Repair of transitional or } \\
\text { complete AVC }\end{array}$ & 5.8 & 4 & 7.2 & 4 & 2.1 & 13 & 0.0 & 13 & 19 & 40 & 4 \\
\hline 3 & RV-to-PA conduit & 4.6 & 7 & 4.6 & 8 & 4.3 & 6 & 0.0 & 13 & 20 & 41 & 6 \\
\hline 3 & Systemic-to-PA shunt & 13.6 & 1 & 11.3 & 2 & 28.4 & 1 & 26.8 & 1 & 1 & 5 & 1 \\
\hline 3 & Tricuspid valvuloplasty & 2.5 & 15 & 3.1 & 11 & 1.5 & 16 & 7.3 & 6 & 6 & 48 & 12 \\
\hline 4 & $\begin{array}{l}\text { Arterial switch operation with } \\
\text { VSD repair }\end{array}$ & 3.6 & 11 & 1.2 & 24 & 3.1 & 11 & 0.0 & 13 & 30 & 76 & 21 \\
\hline 4 & Repair of hypo/IAA & 2.7 & 14 & 1.8 & 17 & 3.3 & 10 & 7.6 & 5 & 5 & 46 & 10 \\
\hline 4 & Repair of TAPVR, $\leq 30 \mathrm{~d}$ & 3.5 & 12 & 2.0 & 15 & 10.1 & 3 & 0.0 & 13 & 26 & 56 & 13 \\
\hline 4 & Repair of truncus arteriosus & 2.4 & 17 & 1.2 & 23 & 3.3 & 9 & 2.1 & 12 & 12 & 61 & 15 \\
\hline 6 & $\begin{array}{l}\text { Norwood: stage } 1 \text { repair of } \\
\text { HLHS }\end{array}$ & 4.6 & 6 & 4.6 & 7 & 11.7 & 2 & 4.8 & 10 & 10 & 25 & 3 \\
\hline 6 & $\begin{array}{l}\text { Norwood: stage } 1 \text { repair of } \\
\text { non-HLHS }\end{array}$ & 2.5 & 16 & 1.5 & 19 & 5.8 & 4 & 7.7 & 4 & 4 & 43 & 8 \\
\hline
\end{tabular}

Columns labeled "\% Total" sum to $100 \%$ and refer to the percent of the event from the specified procedure. RACHS, Risk Adjustment for Congenital Heart Surgery; LOS, length of stay; $A S D$, atrial septal defect; $P A P V R$, partial anomalous venous return; TAPVR, total anomalous pulmonary venous return; $R V O T$, right ventricular outflow tract; $A S$, aortic stenosis (produced by an obstruction in the left ventricle at the aortic valve); TOF, tetralogy of Fallot; VSD, ventricular septal defect; $R V$, right ventricle; $P A$, pulmonary artery; $A V C$, atrioventricular canal; $I A A$, interruption of aortic arch; $H L H S$, hypoplastic left heart syndrome. *Modified rank was created using the rank of the coefficient of variation to break ties in the rank of the percent of excess days.

procedures) applies here. ${ }^{19-21}$ Access in the future to the linked Society of Thoracic Surgeons Congenital Heart Surgery Database and the PHIS Database ${ }^{22}$ to perform a similar analysis as reported in this article could further strengthen the proof of concept our study shows. Perhaps the greatest limitation of our study (or any similar study) is that it does not provide information on what is the most important component of any QI initiative: the quality of the experience for the patient or their family.
When we initiated this study, we intended to obtain comprehensive data related to adverse events, such as those measures reported by others as in Agency for Healthcare Research and Quality safety indicators or the Wisconsinmodified Agency for Healthcare Research and Quality adverse events. However, these measures have not been adjusted or validated for pediatric cardiac surgery, limiting their application at least in their current state. We used a derivative of an algorithm applied to pediatric patients 
undergoing surgery and added the ECMO event rate; we were unable to capture neurologic events that would be an important component of assessing morbidity. Our data set did not allow for examination of unplanned reintervention rates. Future studies, such as those using the linked Society of Thoracic Surgeons-PHIS database, that provide insight on these variables can further help with prioritization schemes. Finally, our data do not explain the reason for the significant variation in care for the various procedures. Perhaps center- or institution-specific features have some impact in this regard. These could be the subject of future investigations.

Our results have the following implications for QI efforts in pediatric cardiac surgery. First, the data might be used as a guide to prioritize local QI efforts at individual institutions based on their case mix. ${ }^{23}$ We have provided a number of "priority lists" based on various ranking algorithms; these can be modified as desired and provide a concept of which areas to focus on to implement QI measures. For professional organizations, our findings might be useful in targeting largescale QI efforts beyond subjective, consensus opinion; other data sets can be used for validation of such schemes or to develop more robust prioritization schemes in an objective manner. Finally, our findings are relevant to current policy discussions regarding healthcare reform and associated costs as one may use similar approaches to identify high-leverage procedures, in terms of their potential for not only improving patient outcomes but also reducing excess cost.

Our study does not assess the extent to which QI could reduce any parameter for each procedure. Therefore, individual organizations and improvement teams would likely want to consider other factors in setting their QI priorities. In particular, it would be important to weight the potential of each procedure for a QI initiative, even though we tried to focus on the higher-volume procedures.

\section{CONCLUSIONS}

Future work should aim to improve our current understanding of processes of care associated with observed outcomes and objectively lead to QI initiatives that improve care across many institutions that currently care for children with congenital heart disease.

\section{References}

1. Welke KF, Diggs BS, Karamlou T, Ungerleider RM. Measurement of quality in pediatric cardiac surgery: understanding the threats to validity. ASAIO J. 2008; 54:447-50.

2. Welke KF, Ungerleider RM. Mortality as an outcome parameter for pediatric heart surgery. ASAIO J. 2006;52:552-5.

3. Welke KF, Shen I, Ungerleider RM. Current assessment of mortality rates in congenital cardiac surgery. Ann Thorac Surg. 2006;82:164-71.

4. Welke KF, Jacobs JP, Jenkins KJ. Evaluation of quality of care for congenital heart disease. Semin Thorac Cardiovasc Surg Pediatr Card Surg Annu. 2005; 157-67.

5. Campbell DA Jr, Henderson WG, Englesbe MJ, et al. Surgical site infection prevention: the importance of operative duration and blood transfusion-results of the first American College of Surgeons-National Surgical Quality Improvemen Program Best Practices Initiative. J Am Coll Surg. 2008;207:810-20.

6. Neuman HB, Michelassi F, Turner JW, Bass BL. Surrounded by quality metrics: what do surgeons think of ACS-NSQIP? Surgery. 2009;145:27-33.

7. Schilling PL, Dimick JB, Birkmeyer JD. Prioritizing quality improvement in general surgery. J Am Coll Surg. 2008;207:698-704.

8. Dillon P, Hammermeister K, Morrato E, et al. Developing a NSQIP module to measure outcomes in children's surgical care: opportunity and challenge. Semin Pediatr Surg. 2008;17:131-40.

9. Hutter MM, Rowell KS, Devaney LA, et al. Identification of surgical complications and deaths: an assessment of the traditional surgical morbidity and mortality conference compared with the American College of Surgeons-National Surgical Quality Improvement Program. J Am Coll Surg. 2006;203:618-24.

10. Jenkins KJ, Gauvreau K. Center-specific differences in mortality: preliminary analyses using the Risk Adjustment in Congenital Heart Surgery (RACHS-1) method. J Thorac Cardiovasc Surg. 2002;124:97-104.

11. Jenkins KJ, Gauvreau K, Newburger JW, Spray TL, Moller JH, Iezzoni LI. Consensus-based method for risk adjustment for surgery for congenital heart disease. J Thorac Cardiovasc Surg. 2002;123:110-8.

12. Rice-Townsend S, Hall M, Jenkins KJ, Roberson DW, Rangel SJ. Analysis of adverse events in pediatric surgery using criteria validated from the adult population: justifying the need for pediatric-focused outcome measures. $J$ Pediatr Surg. 2010;45:1126-36

13. O'Brien SM, Clarke DR, Jacobs JP, et al. An empirically based tool for analyzing mortality associated with congenital heart surgery. J Thorac Cardiovasc Surg. 2009;138:1139-53.

14. Jenkins KJ. Risk adjustment for congenital heart surgery: the RACHS-1 method. Semin Thorac Cardiovasc Surg Pediatr Card Surg Annu. 2004;7:180-4.

15. Brown KL, Ridout DA, Goldman AP, Hoskote A, Penny DJ. Risk factors for long intensive care unit stay after cardiopulmonary bypass in children. Crit Care Med. 2003;31:28-33.

16. Petrucci O, O’Brien SM, Jacobs ML, Jacobs JP, Manning PB, Eghtesady P. Risk factors for mortality and morbidity after the neonatal Blalock-Taussig shunt procedure. Ann Thorac Surg. 2011;92:642-52.

17. Jacobs JP, O'Brien SM, Pasquali SK, et al. Variation in outcomes for benchmark operations: an analysis of the Society of Thoracic Surgeons Congenital Heart Surgery Database. Ann Thorac Surg. 2011;92:2184-92.

18. Jacobs JP, O'Brien SM, Pasquali SK, et al. Variation in outcomes for riskstratified pediatric cardiac surgical operations: an analysis of the STS Congenital Heart Surgery Database. Ann Thorac Surg. 2012;94:564-72.

19. Cronk CE, Malloy ME, Pelech AN, et al. Completeness of state administrative databases for surveillance of congenital heart disease. Birth Defects Res A Clin Mol Teratol. 2003;67:597-603.

20. Frohnert BK, Lussky RC, Alms MA, Mendelsohn NJ, Symonik DM, Falken MC. Validity of hospital discharge data for identifying infants with cardiac defects. $J$ Perinatol. 2005;25:737-42.

21. Strickland MJ, Riehle-Colarusso TJ, Jacobs JP, et al. The importance of nomenclature for congenital cardiac disease: implications for research and evaluation. Cardiol Young. 2008;18(Suppl 2):92-100.

22. Pasquali SK, Jacobs JP, Shook GJ, et al. Linking clinical registry data with administrative data using indirect identifiers: implementation and validation in the congenital heart surgery population. Am Heart J. 2010;160:1099-104.

23. Jacobs JP, Lacour-Gayet FG, Jacobs ML, Clarke DR, Tchervenkov CI, Gaynor JW, et al. Initial application in the STS congenital database of complexity adjustment to evaluate surgical case mix and results. Ann Thorac Surg. 2005;79: 1635-49; discussion 1635-1649.

\section{Discussion}

Dr James Jaggers (Aurora, Colo). As you describe, measurement of quality and performance in the management of our patients with congenital heart disease is challenging because of the vast variety of congenital defects, the variability of presentation, and the severity of illness. It makes it difficult for even complex analyses like this one to capture that. I do like your idea of a prioritization system, something that takes into account not only the mortality figures but also those areas that we know are problems (eg, reintervention, readmission). You use the PHIS database, 
which is a powerful tool and is becoming increasingly used in our field. But it has important limitations as you described. It is retrospective and observational. It is fraught with coding errors, and it captures charges but not cost. It does have a lot of power advantages, so eventually efforts like this to improve our quality are going to take a combination of different databases, such as registries and the administrative databases. With that comment aside, I have a couple questions for you.

Why did you use the RACHS system in your prioritization rather than the more newly combined stratification system, the European Association for Cardio-Thoracic Surgery (EACTS)/Society of Thoracic Surgeons (STS)? One of the reasons you did this study seems to be because you did not like the consensus-based classification. Why not use a data-derived classification system like the EACTS-STS system?

Dr Eghtesady. Simplistically, because the RACHS is an easy algorithm that allows pulling procedures out of administrative databases based on International Classification of Diseases 9th Revision codes. You basically have to access the STS/EACTS database. There is no algorithm that you can apply to the administrative database to be able to pull that data, but I think one could do exactly the same thing with the STS database, which is ease of access to the PHIS database and being able to pull the data using the RACHS algorithm.

Dr Jaggers. Just by way of clarification, when you talk about LOS in your study, does that include the preoperative LOS or is this strictly postoperative LOS?

Dr Eghtesady. No, it is from admission to discharge, so there could be a period of preoperative stay included in that.

Dr Jaggers. That is an important distinction when we start comparing different databases and outcomes that are related to LOS. I am always a little skeptical about complication rates in the PHIS database. As you know, hospitals get reimbursed according to these diagnosis-related groups and the rates of complications. Is there any way within your study that you can reassure us that the complication rates are not significantly different between institutions and different payors?

Dr Eghtesady. Yes and no. You are absolutely right, and I am skeptical of them to some extent. With that said, just looking at
ICU LOS, which others have shown to be a surrogate marker of complications, the data (ie, the prioritization and all that) still hold and correlated with the events rate that we saw, so even though we may be undercapturing the events and this is a derivation of a derivation, there is a lot of reach there if you will. I think the data you see are not necessarily inaccurate. I think the data are underrepresenting; we are not seeing all the complications that should be there. Additional effort needs to go into providing definitions. For example, neurologic events is missing, and specifically the reason is until 2010 the database, PHIS database, did not have a category to identify whether the child presenting at admission had a neurologic problem at baseline or not, so using the definitions that have been used in the past would have given us an unmeaningful response. The database includes select events and is not completely accurate, but my confidence lies in the fact that it correlates nicely with ICU LOS, which is a reasonable assumption to say it is a surrogate for complications.

Dr Jaggers. As you have described, the PHIS database's advantage is that it contains more than 5 million inpatient encounters and with that comes charge data for which cost data can be derived. We are going to be judged on value essentially and quality and cost. What is your opinion as you look forward? Do you think it is time for us to start including cost within these prioritization screens? What do you think about that?

Dr Eghtesady. Great question, and the short answer is yes. I talked about it with Matt Hall, but the reality was for us to be able to pull that off was going to be challenging because it seemed like we had so much in there. You and Ross Ungerleider were kind enough to provide reference to me, an article that you guys had published a long time ago where you looked at costs at Duke with 140 procedures and looked at variation and how ASD repair was a reliable cost versus VSD, which was more variable. That is an important thing to look at, and in the future that would be one of the things that would definitely be worth looking at.

Dr Jaggers. Thank you. 